\section{Europe woos Japan}

\section{London \& Tokyo}

EUROPEAN and Japanese physicists are poised to overcome the usual reluctance of the world's three main scientific blocs Europe, Japan and the United States - to collaborate with one another in 'big science' projects. Hampered by a shortfall in funding of almost $£ 10$ million, a European group plans to ask physicists at Nagoya University in Japan to work with them to build a large radar array in the Arctic Circle.

The collaboration would rescue the European solar-terrestrial physics community's most important project for the 1990s and save the Japanese from spending the money to build a separate system that would deliver basically the same data as the planned European radar array. But unless the European and Japanese groups can settle their differences over the design of the system, the partnership may never get off the ground.

Both the European Incoherent Scatter Radar (EISCAT) consortium, financed by funding bodies in six European countries, and a group at Nagoya University in Japan have been planning to build radar arrays on the island of Svalbard in order to study the interaction between the solar wind and the Earth's upper atmosphere and magnetic field. (Using incoherent scatter radar, physicists can study the movement, density and temperature of plasma in the ionosphere, several hundred kilometres above sea level.) At Svalbard, where it is dark at noon in winter, radar monitoring of the ionosphere can be combined with optical observations of auroras.

Originally, EISCAT planned to build a Polar Cap Radar consisting of three steerable radar dishes, at a cost of more than $£ 20$ million. The proposal was advanced most strongly by British physicists, but the recent financial difficulties of the Science and Engineering Research Council (SERC) have forced the British to delay their $£ 4$ million contribution for two years (see Nature 349, 551; 14 February 1991). Even after this time, funding from SERC is not guaranteed.

At a meeting in Grenoble earlier this month, EISCAT council members from France, Germany, Sweden, Norway and Finland agreed reluctantly to finance the bulk of the project until SERC can afford to contribute. But even with the still-uncertain British contribution, EISCAT expects to have only $£ 12$ million to spend, as the world economic recession restricts spending on science in most countries, and the German contribution is further constrained by the cost of reunification.

To get around the funding problems, EISCAT would like to join forces with the Nagoya University group, says EISCAT council member Stan Cowley from Imperial College, London. But merging the two projects may prove difficult. The Japanese, led by Nobuo Matuura, propose to build a able platform.

\section{Munich} Aviation. phased array radar consisting of several thousand small radar transmitters arranged in a grid. The advantage of this system is that the radar beam can be steered around the sky electronically, as opposed to the mechanical steering of a radar dish. With a phased array radar, the beam can be redirected many times a second, whereas steerable dishes take several minutes to reposition mechanically. Matuura says he would like to collaborate with the Europeans, but only if EISCAT agrees to build a phased array radar.

Cowley agrees that the phased array design is technically superior, but he is worried about the cost. Cowley estimates that to meet EISCAT's specifications, a phased array radar would cost about $£ 50$ million. The European proposal requires a radar beam that can be steered over almost the whole of the sky above Svalbard. To do this, a phased array system (which can steer its beam through only a limited angle from the vertical) would have to be built on a tilt-

Matuura replies that phased array systems are "not always as expensive as thought by the Europeans". A US-made phased array OTTO LILIENTHAL

\section{Early flight pioneer commemorated}

IN 1991 Germany celebrates the 100th anniversary of the first flight by aviation pioneer Otto Lilienthal (1848-96), whose scientific studies of the flight of birds led to the first reproducible glider flights.

Lilienthal, whose research was an inspiration to the Wright brothers, died in a glider accident in August 1896. The

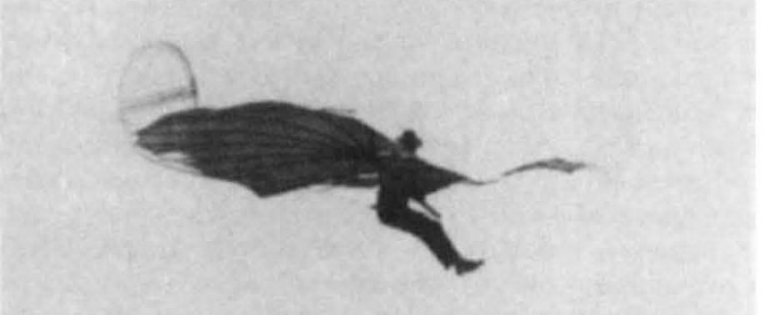
Wrights later made a gift of $\$ 1,000$ to Lilienthal's widow Agnes in gratitude for his contributions to aviation, which they had read about in the literature.

The 2,000 glider flights Lilienthal made between 1891 and his death kept him in the air longer than all previous aviators combined who had flown in heavier-than-air craft. The photograph shows Lilienthal on one of his Iongest flights in the Rhinower Mountains near Berlin. Some of his flights reached 250 metres.

Last week marked the opening of a special exhibition on Lilienthal at the Deutsches Museum in Munich, Germany's foremost science museum, which displays reconstructions of two LilienOn a wing and a prayer.

thal gliders (a single- and a double-decker) as well as photographs and documentation with some English translations.

A poor student at school, Lilienthal became a successful engineer whose systematic aerodynamic studies of bird flight led him to realize the importance of a cambered (arched) wing. He published his results in 1889 in a book called Bird Flight as the Basis of

Steven Dickman 